\title{
Study on Construction Process of MOOC Course
}

\author{
Yong $\mathrm{Luo}^{1 *}$, Jianping $\mathrm{Li}^{1}$, Jianmin Zhu ${ }^{1}$, Zheng Xie ${ }^{1}$, Xiaorong $\mathrm{Hu}^{1}$, Guochang Zhou ${ }^{1}$, and Zhihao Xiao ${ }^{1}$ \\ 1 College of Science, National University of Defense Technology, Changsha, China; \\ Email: yngluo@163.com*Yong Luo
}

\begin{abstract}
With the rapid development of MOOC, course resources are quickly constructed. Because of lack of experience, the quality of many courses is affected. At the same time, there are still many inefficient teams. Therefore, it is very necessary to study scientific MOOC construction process. In the article, we introduced our experience in building four MOOC courses and proposed a scientific construction process. From the three stages of course planning, preparation courses, and video production, this article details the process of MOOC production. It can help teachers prepare MOOC. This process can ensure the quality of resource construction and increase work efficiency. Therefore, such research can promote the development of MOOC.
\end{abstract}

\section{Keywords-MOOC; Construction Process; Course planning}

\section{INTRODUCTION}

MOOC is the large open online courses. Courses are provided by internationally renowned university and shared through the network [1]. It enables global sharing of quality course. Coursera, Udacity, edX are currently the three largest providers in the world.

Its philosophy is to enable global learners to share quality resources through information technology and web technologies [2]. MOOC have a complete set of teaching modes. Including registration, watching video lectures, quizzes, assignments, discussions, exams, graduation, certificates and other processes. These teaching models to learners brought a new experience and give chance to get involved in high education. At the same time, through sharing the resources, the college courses can also be improved.

Although it has been rapid development and recognition, but there are still many controversies. How to use online course resources scientifically is a common concern. MOOC is currently facing such problems as high dropout rates, low resource utilization and lack of an effective profit model. MOOC courses often enroll tens of thousands of students, but often the last certificate students only $1 \%$. The reasons for these problems are many, and the quality of the course production is a very important factor. Many of the MOOC course videos are now converted from classroom videos. The auxiliary resources of the course are also completely copied from classroom teaching. The courses produced in this way are not suitable for online learning. On the other hand, due to the lack of an efficient MOOC production process, curriculum production is inefficient. Therefore, the scientific MOOC curriculum production process is of great significance for its development.

There is very little research on the processes and specifications for MOOC production. Some recent studies include the following. Formanek (2018) [1] analysed and studied motivations of college students studying MOOC courses. Lloyd et al. (2017) [2] calculated and analysed MOOC course learning behaviours and learning performance data. Andrew (2017) [3] based on the characteristics of chemistry courses, studies how to enable more effective communication among learners and improve their learning in MOOC. AlarioHoyos (2016) [4] analysed MOOC learning behaviours and its effectiveness as a means of assessing MOOC. Hone et al. (2016) [5] analysed the factors affecting the retention of MOOC learning through the questionnaire. Mackness et al. (2015) [6] analysed the prospects and challenges of MOOC development. Margaryan et al. (2015) [7] analysed MOOC teaching quality and its influencing factors. Phan (2016) [8] analysed students' performance in participating in the MOOC course. And do a comparative study of classroom learning and online learning. Bart Pursel et al. (2016) [9] studied MOOC learners' demographic data, learning behaviours and course interaction data. Stich (2017) [10] analysed the MOOC in the United States and found that the platform blindly pursued the number of courses but neglected the service to learners.

Our MOOC team has already built four MOOC courses. In this process, some experience in the production of MOOC courses has been accumulated. This article will introduce the optimized MOOC course production process.

\section{COURSE PLANNING}

Planning is the first step in building MOOC, and also a key step. It takes into account the overall issues of the team's organizational structure, operating model, curriculum resource model, and content templates. The goal of this work is to design a comprehensive development program for the course. In this session, it mainly includes the two stages of developing task planning and writing content templates. 


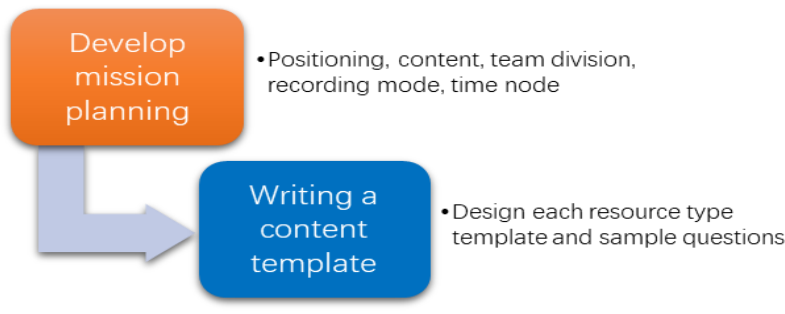

Fig. 1 MOOC planning

\section{A. Develop mission planning}

Mission planning mainly includes course positioning, content outline, team composition, task division, recording mode, and time nodes. Course positioning refers to the goals of the course and the main user groups. It affects the difficulty of the course and the composition of the content. The course positioning will be able to define the basic modules and user groups.

After the course positioning is clearly defined, the content outline can be designed. The content outline is designed to match the course positioning. It includes the chapter settings of the course and the content of each lecture. This process often requires the team to study and analyze. It is necessary to ensure the integrity of the content, but also to consider the amount of knowledge of the teaching unit.

Team personnel generally remain stable, but it will also adjust as the course progresses. Our team was 10 at the time of building the first MOOC class and there were 11 people up to now. The team members have different divisions of labor and the overall staff is stable. This model can maximize the advantages of the team.

The division of tasks is mainly to optimize the division of work within the team. Our team members will respectively undertake the following tasks: video lectures, video quizzes, research questions upload, course maintenance, task planning, study questions configuration, course maintenance, video subtitles proofreading, organization coordination, exercise proofreading, problem configuration, courseware production, exercises Upload and platform technologies. This is a complicated but very important job.

The recording and broadcasting mode determines the basic process of course video production. The recording mode adopted by our team was recorded in studio and combined with computer screen recording. Through post-production, the lecture video and the computer screen are combined to create a lesson video. Of course, there are other types. For example, you can record video in the classroom and make the teacher's class video into MOOC video. There is also a type of micro video recorded by the Khan Academy. Teachers can record in any environment. It can be a teacher writing and explaining on a piece of paper.

Determining time nodes is also an important part of MOOC production. Designing a scientific and reasonable MOOC time node can ensure the progress of the course construction. It enables team members to keep the same progress. At the same time, it allows team members to plan and design their own work plans. This will increase the efficiency of the members and ensure the quality of the courses.

\section{B. Writing content template}

The second important task of planning is to write content templates. Content templates determine the basic form of course modules and course content. The process needs to be analyzed and discussed by team members. It often takes several rounds of research and revision to finalize. The design of the template directly determines the quality of the MOOC course.

According to the basic unit of MOOC, we define the module as a knowledge point in a lecture. As shown in the above figure, the module can be divided into a module summary and a teaching unit. The module summary includes the learning objectives, module guidance, focus and difficult guidance, and references. The teaching unit includes course videos, exercises, homework and other auxiliary resources.

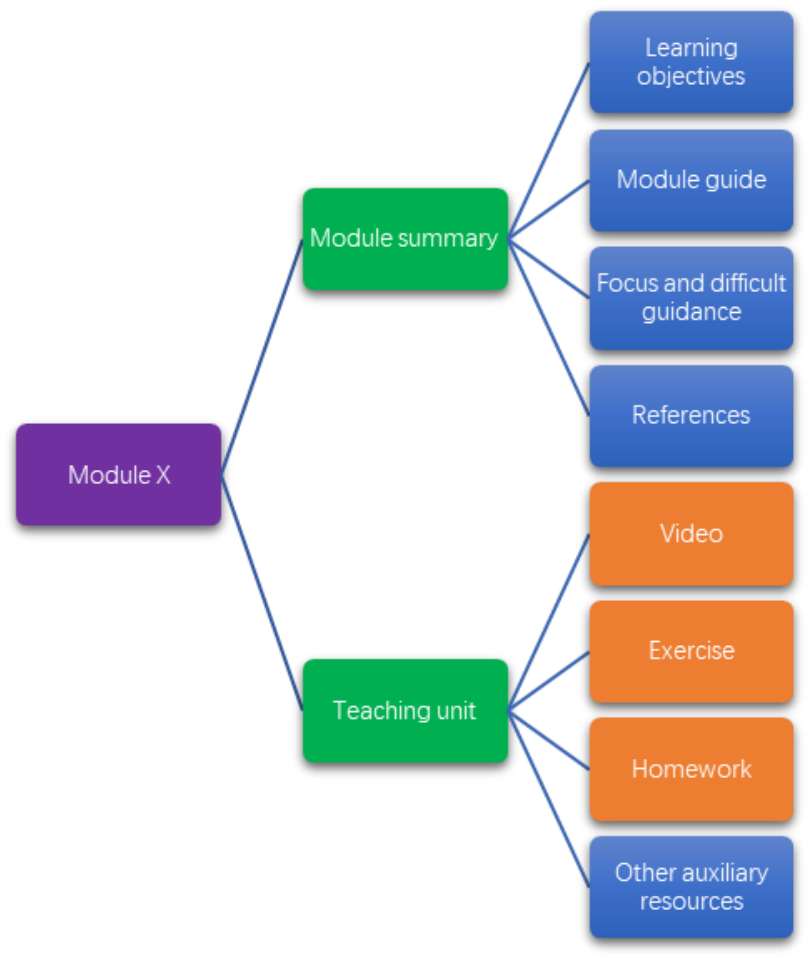

Fig. 2 Module design

MOOC production can be divided into four aspects: lectures, exercises, unit tests and final exams. The lectures mainly include an abstract and a typical example. Exercises include objective questions (judgment, choice) and subjective questions. The last is unit testing and final testing. These resource elements all need to design corresponding templates and sample questions. This establishes a standard for the design of resources for the entire course. This is a guarantee of the quality of MOOC construction. Also, in general, unit tests and final tests need to match the difficulty of the course certificate. When designing the test questions, it is necessary to consider factors such as learning status, level of mastery, and input interface of online learning. The number and difficulty of test 
questions must be appropriate. So template production is very important.

\section{PREPARE LESSONS}

The lesson preparation stage is to prepare course resources and content. It is one of the core steps in the construction of MOOC. Preparation of MOOC resources takes a lot of time and effort. In general, each part of the work can be decomposed and completed by team members. The team can also assign work to each member according to chapters. Because the level of resource construction ultimately determines the overall level of the course. Resource assessment and analysis are important steps to ensure quality. The preparation process of MOOC includes four stages: the preparation of the draft, the revision of each lecture, the preparation of the PPT, and the preparation for video recording.

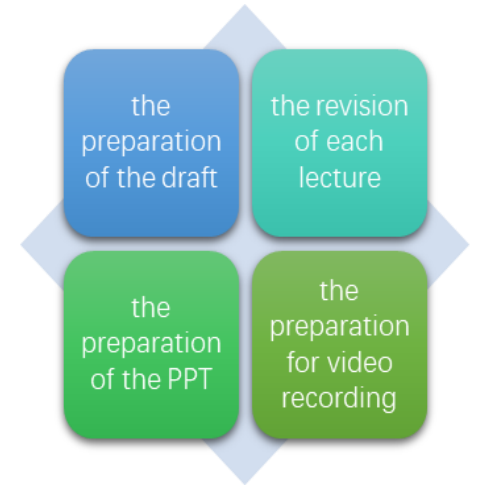

Fig. 3 Prepare lessons

\section{A. Preparation of the draft}

The members of the team wrote the first draft of the course resources according to their own tasks. This will allow each team member to play their own advantages. And, it greatly improves the efficiency of resources construction. On the other hand, because each member designs the assigned resources, quality can be guaranteed.

\section{B. Revision of each lecture}

Video lecturers are responsible for the finalization of each of their own speeches. Each lecture content and organization form will conform to the instructor's teaching habits. It ensures the smoothness of the teaching process, and also reflects the lecturer's style of teaching.

\section{Preparation of the PPT}

For the PPT of the course, we demand a unified production. This is mainly to ensure the unity of the PPT format. And, we usually choose professional PPT production staff. It guarantees the quality and standardization of the course.

\section{Preparation for video recording}

The final stage is for the teacher to prepare for video recording based on the content. Our team will prepare lessons collectively. For the course video and lecture process, we conduct a very detailed analysis. These tasks include analyzing the content and organization of the curriculum and examining the design of examples.

\section{VIDEO PRODUCTION}

The core resource of MOOC is video. Learning MOOC courses depends on course video. So the production of the course video is the most important job. The course video production process includes four stages: recording video in studio, video editing, video proofreading and revision, and course introduction video production.

\section{A. Recording video in studio}

a) Many MOOC courses are often shot at the same time, which requires the studio to develop a corresponding shooting plan. The MOOC team must prepare the appropriate resources according to the shooting plan. Video lecturers need to allocate their own time and energy. Keep the best physical condition recording video of the lesson. In addition, video recording and resource preparation are carried out in parallel. Each team member must complete the corresponding work according to the time node and the resource template. Only after careful division and cooperation can the course resources and video recording be successfully completed.

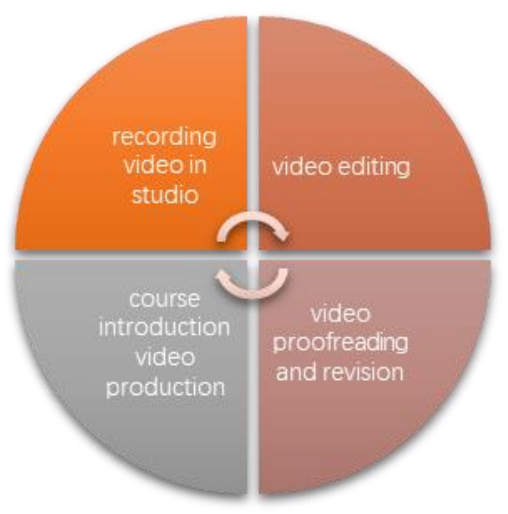

Fig. 4 Video production process 


\section{B. Video editing}

After video recording is completed, professionals are required to make video clips according to the progress requirements. General video recording includes video recording and screen recording. The two parts are synchronous. In the later video clips need to combine the two. We can insert the teacher's image in the PPT image. Teachers or presentations can also be displayed separately. These designs rely on the planning and design of video editing staff. Of course, video recording teachers and team members can make changes to video clips. After everyone's efforts, we designed a video that meets the requirements.

\section{Video proofreading and modification}

When the video editing is completed, the corresponding subtitles need to be configured. Subtitled video is the finished product. However, during the recording process, there were some mistakes in the teacher's course, or the configuration of the subtitles. This requires proofreading and making changes to the video. Our team asked the instructor to perform proofreading tow times and another teacher to do one times. The purpose of this is to minimize errors and ensure the accuracy of the content. Once the video is released, its problems and mistakes will remain. Therefore, video proofreading and modification are very important tasks.

\section{Course introduction video}

The course introduction video includes the basic situation of the course, as well as the course production team and other information. So, course introduction video is often the basis for learners to choose courses. It is a window for learners to understand the course. The content is refined and attractive. Therefore, the creation of the course introduction video should attract the attention of MOOC producers. The production process includes scripting, recording, professional production (guidance, camera, broadcast, material, and clip).

\section{CONCLUSION}

The quality of MOOC resources is related to the standard process of construction. Only the development of scientific processes can ensure the quality of the curriculum. At the same time, it can also improve the efficiency of resource construction. The construction process proposed in this paper comes from our team's experience in building four courses. It is hoped that these experiences will help teachers who will be doing MOOC courses.

\section{REFERENCES}

[1] Formanek, M., Wenger, M., Buxner, S., Impey, C.D. (2018). Motivational Differences between MOOC and Undergraduate Astronomy Students. American Astronomical Society, 231.

[2] Lloyd, P. R. (2017). Participation patterns in a massive open online course (MOOC) about statistics. British Journal of Educational Technology, 48(6), 1295-1304.

[3] Andrew, A. (2017). The nature and level of learner-learner interaction in a chemistry massive open online course (MOOC). Journal of Computing in Higher Education, 29(3), 411-431.

[4] Alario-Hoyos, C., Muñoz-Merino, P. J., Pérez-Sanagustín, M., et al (2016). Who are the top contributors in a MOOC? Relating participants' performance and contributions. Journal of Computer Assisted learning, 32(3), 232-243

[5] Hone, K. S., \& El Said, G. R. (2016). Exploring the factors affecting MOOC retention: A survey study. Computers \& Education, 98, 157-168.

[6] Mackness, J., \& Bell, F. (2015). Rhizo14: A rhizomatic learning cMOOC in sunlight and in shade. Open Praxis, 7(1), 25-38.

[7] Margaryan, A., Bianco, M., \& Littlejohn, A. (2015). Instructional quality of massive open online courses (MOOCs). Computers \& Education, 80, 77-83.

[8] Phan, T., McNeil, S. G., \& Robin, B. R. (2016). Students' patterns of engagement and course performance in a massive open online course. Computers \& Education, 95, 36-44.

[9] Pursel, B. K., Zhang, L., Jablokow, K. W., Choi, G. W., \& Velegol, D. (2016). Understanding MOOC students: motivations and behaviours indicative of MOOC completion. Journal of Computer Assisted learning, 32(3), 202-217.

[10] Stich, A. E., \& Reeves, T. D. (2017). Massive open online courses and underserved students in the United States. The Internet and Higher Education, 32, 58-71. 